\title{
Performance Evaluation and Comparison of Battle Tanks through Combined AHP-DEA Approach
}

\author{
Mukesh Bansal \\ IAS, Raipur, \\ Chhattisgarh, India
}

\author{
Sanjeet Singh \\ Decision Sciences Area \\ Indian Institute of \\ Management Lucknow \\ Lucknow (U.P.), India
}

\author{
Remica Aggarwal \\ Recventures Education \\ Services Private Limited \\ Delhi, India
}

\author{
V. K. Aggarwal \\ Recventures Education \\ Services Private Limited \\ Delhi, India
}

\begin{abstract}
All major weapon system acquisition and development programs in the defense forces have a long term effect on the defense preparedness and economy of country. Therefore the cost -effective analysis of such systems is very important. For a comparison of cost effectiveness of two tanks for example , their relative ratings can be used as effective index. A model has been developed in this paper which evaluate the performance of tanks using DEAHP approach . Data Envelopment Analysis (DEA) has been proposed in this paper to generate local weights of the alternatives from pairwise comparison judgement matrices used in the Analytic Hierarchy Process (AHP). DEA is further proposed to aggregate the local weights of alternatives in terms of different criteria to compute final weights . The underlying assumption behind the approach is explained. The approach uses the qualitative information given by experts in tank warfare and technology to determine the relative ratings of the tanks. The method can be useful in the cases where adequate data for rigorous analysis is not available .
\end{abstract}

\section{Keywords}

Analytic Hierarchy Process, Data Envelopment Analysis , Multiple Criteria Decision Making

\section{INTRODUCTION}

Managing the development of a major weapon system is, to a great extent, the management of risk . Various weapon system development programs influences defense status and economy of the country . Cost effective analysis, therefore, of such system is imperative. But such cost effective analysis is not that simple as there are situations where sufficient information on operational features of the system (especially for those systems which are under development in R\&D laboratories) is required. In such cases performance evaluation of such system may be based on opinion of the experts in weapon technology \& warfare. For such studies , Saaty [1,2] suggested a technique called Analytic Hierarchy Process (AHP). This management technique has been developed to handle the multiple criteria decision making (MCDM) problems using qualitative evaluation of the systems by experts from relevant disciplines \& profession. The same technique can be adopted in evaluating the performance of the weapon system by rating its effectiveness in relation to another well-known existing system. Data envelopment analysis (DEA) is one of the most popular tools in production management literature for performance measurement. The goal of DEA is to determine the productive efficiency of a system or decision-making-unit (DMU) by comparing how well the DMU converts inputs into outputs, while the goal of MCDM is to rank and select from a set of alternatives that have conflicting criteria. It has been recognized for more than a decade that the MCDM and DEA formulations coincide if inputs and outputs can be viewed as criteria for performance evaluation, with minimization of inputs and/or maximization of outputs as associated objectives. To explain the application of AHP \& DEA in the performance evaluation of tanks, first we have to identify the factors that affect the performance of a tank in the battlefield [4-7].

Paper is arranged as follows . Section 1.1 deals with the literature on main battle tanks \&major factors that determines the tank's effectiveness in the battle. Section 1.2 deals with the techniques AHP, DEA, DEAHP . Section 2 deals with the empirical illustration of the problem and section 3 deals with the analysis of the problem using DEAHP approach . Finally, section 4 concludes the paper

\subsection{Weapon systems : main battle tanks}

A tank is a, armored tracked fighting vehicle designed for front-line combat and combines strong strategic and tactical offensive and defensive capabilities. Tanks were first manufactured during World War I in an effort to break the bloody deadlock of trench warfare. The British Army was the first to field a vehicle that combined three key characteristics: mobility over barbed wire and rough terrain, armor to withstand small arms fire and shrapnel and the firepower required to suppress or destroy machine gun nests and pillboxes. The three traditional factors determining a tank's effectiveness in battle are its firepower, protection/survivability, and mobility. In practical terms, the cost to manufacture and maintain a given tank design is also important in that it determines how many tanks a nation can afford to field. Firepower is the ability of a tank to identify, engage, and destroy a target. Protection is the tank's ability to resist being detected, engaged, and disabled or destroyed by enemy fire. Mobility includes tactical (short range) movement over the battlefield including over rough terrain and obstacles, as well as strategic (long range) mobility, the ability of the tank to be transported by road, rail, sea, or air to the battlefield. It is not possible to maximize firepower, protection and mobility simultaneously. For example, increasing protection by adding armor will result in an increase in weight and therefore decrease mobility; increasing firepower by installing a larger gun will force the designer to sacrifice speed or armor to compensate for the added weight and cost. Therefore with respect to each of the three factors, several tank performance parameters (sub-factors) can be identified e.g rate of fire, maximum firing range, manoeuring speed, armor thickness etc. this information can be organized into a hierarchical structure where the last level of hierarchy involves the alternatives to be compared which include the tank whose performance has to be evaluated and some other well -known tanks whose performance can be treated as a standard for comparison .Now let us discuss the AHP technique as suggested by Saaty [1-2 ]and how AHP linked 
with DEA can be used to give the performance of tanks.

\subsection{Techniques: AHP, DEA, DEAHP}

\subsubsection{Analytic hierarchy process [1,2]}

The AHP, developed by [1,2], has been studied extensively and used in almost all the applications related with multiple criteria decision making(MCDM) in the last 20 years. The AHP consists of three main operations, including hierarchy construction, priority analysis , and consistency verification. First of all, the decision makers need to break down complex multiple criteria decision problems into its component parts of which every possible attributes are arranged into multiple hierarchical levels. After that, the decision makers have to compare each cluster in the same level in a pairwise fashion based on their own experience and knowledge. For instance, every two criteria in the second level are compared at each time with respect to the goal, whereas every two attributes of the same criteria in the third level are compared at a time with respect to the corresponding criterion. Since the comparisons are carried out through personal or subjective judgments, some degree of inconsistency may be occurred. To guarantee the judgments are consistent, the final operation called consistency verification, which is regarded as one of the most advantages of the AHP, is incorporated in order to measure the degree of consistency among the pairwise comparisons by computing the consistency ratio. If it is found that the consistency ratio exceeds the limit, the decision makers should review and revise the pairwise comparisons. Once all pairwise comparisons are carried out at every level, and are proved to be consistent, The judgments can then be synthesized to find out the priority ranking of each criterion and its attributes $[1,2,3]$.

\subsubsection{Data Envelopment Analysis (DEA)}

DEA has been successfully employed for assessing the relative performance of a set of firms, usually called the DMU, which use a variety of identical inputs to produce a variety of identical outputs. The concept of Frontier Analysis suggested by Farrel [8] forms the basis of DEA, but the recent series of discussions started with the article by $[9,10,11]$.

Assume that there are N DMUs producing $J$ outputs using $I$ inputs. Let the $m^{\text {th }}$ DMU produce outputs $y_{m j}$ using $x_{m i}$ inputs. The objective of the DEA exercise is to identify the DMU that produces the largest amounts of outputs by consuming the least amounts of inputs. This DMU (or DMUs) is considered to have an efficiency score equal to one. The efficiencies of other inefficient DMUs are obtained relative to the efficient DMUs, and are assigned efficiency scores between zero and one. The efficiency scores are computed using mathematical programming. A typical DEA model used here is

$$
\begin{aligned}
& . \operatorname{Max} Z=\mathrm{V}_{\mathrm{m}}^{\mathrm{t}} \mathrm{Y}_{\mathrm{m}} \\
& \text { s.t. } \quad \mathrm{U}^{\mathrm{t}}{ }_{\mathrm{m}} \mathrm{X}_{\mathrm{m}}=1 \\
& \mathrm{~V}_{\mathrm{m}}^{\mathrm{t}} \mathrm{Y}_{\mathrm{m}}-\mathrm{U}^{\mathrm{t}}{ }_{\mathrm{m}} \mathrm{X}_{\mathrm{m}} \leq 0 \\
& \mathrm{~V}_{\mathrm{m}}^{\mathrm{t}}, \mathrm{U}_{\mathrm{m}}^{\mathrm{t}} \geq 0
\end{aligned}
$$

$X_{m}$ and $Y_{m}$ are the matrices of inputs and outputs, respectively, for the $m^{\text {th }}$ DMU. This model can be used to calculate the DEA efficiency score of $m^{\text {th }}$ DMU. The optimal objective function values of Model, when solved, represent the efficiency score .This DMU is relatively efficient if and only if their optimal objective function value equals unity. Efficiency scores for inefficient units are between zero and one. For inefficient units, DEA also provides those efficient units (namely peers), which the inefficient units can emulate to register performances that could improve their efficiency scores. This model assumes constant returns to scale (CRS) which is said to prevail when an increase of all inputs by $1 \%$ leads to an increase of all outputs by $1 \%$.

\subsubsection{DEAHP ( Synthesis of DEA \& AHP in deriving weights)[11]}

In this section, it is proposed that DEA concepts can be used in the last two steps of applying AHP to a decision problemnamely, deriving local weights from a given judgment matrix and aggregating local weights to get final weights. Efficiency calculations using DEA require outputs and inputs. Each row of the judgment matrix is viewed as a DMU and each column of the judgement matrix is viewed as an output. Thus a judgement matrix of size $n \times n$ will have $n$ DMUs and $n$ outputs. Note that the entries of the matrix are viewed as outputs as they have the characteristics of outputs. Since DEA calculations cannot be made entirely with outputs and require at least one input, a dummy input that has a value of 1 for all the DMUs is employed. Table I and table II below shows the traditional AHP view and the DEA view proposed by Ramanathan [12].

Table1. Traditional AHP View

\begin{tabular}{|c|c|c|c|c|}
\hline & Criterion1 & Criterion2 & $\cdots$ & Criterion $\boldsymbol{n}$ \\
\hline Alt 1 & 1 & $\mathrm{a}_{12}$ & & $\mathrm{a}_{1 \mathrm{n}}$ \\
\hline Alt 2 & $1 / \mathrm{a}_{12}$ & 1 & & $\mathrm{a}_{2 \mathrm{n}}$ \\
\hline$\cdots \cdots$ & $\cdots$ & $\cdots$ & $\cdots$ & $\cdots$ \\
\hline Alt $\mathrm{N}$ & $1 / \mathrm{a}_{1 \mathrm{n}}$ & $1 / \mathrm{a}_{2 \mathrm{n}}$ & & 1 \\
\hline
\end{tabular}

Table 2. Proposed DEA View

\begin{tabular}{|c|c|c|c|c|c|}
\hline & $\begin{array}{c}\text { Output } \\
\boldsymbol{1}\end{array}$ & $\begin{array}{c}\text { Output } \\
\boldsymbol{2}\end{array}$ & $\boldsymbol{\cdots}$ & $\begin{array}{c}\text { Output } \\
\boldsymbol{n}\end{array}$ & $\begin{array}{c}\text { Dummy } \\
\text { input }\end{array}$ \\
\hline DMU1 & 1 & $\mathrm{a}_{12}$ & & $\mathrm{a}_{1 \mathrm{n}}$ & 1 \\
\hline DMU2 & $1 / \mathrm{a}_{12}$ & 1 & & $\mathrm{a}_{2 \mathrm{n}}$ & 1 \\
\hline$\cdots \cdots$ & $\cdots$ & $\cdots$ & $\cdots$ & $\cdots$ & $\cdots$ \\
\hline $\begin{array}{c}\text { DMU } \\
\mathrm{n}\end{array}$ & $1 / \mathrm{a}_{1 \mathrm{n}}$ & $1 / \mathrm{a}_{2 \mathrm{n}}$ & & 1 & 1 \\
\hline
\end{tabular}

It is proposed that the efficiency scores calculated using DEA models could be interpreted as the local weights of the DMUs. When applied to a consistent matrix, for which weights are known, DEA correctly estimates the true weights. While computing the final weights of the main factors as well as the performance rating of tanks we are proving the theorem as given below:

Theorem [12] Let the local weights of alternatives with respect to different criteria be given by

$\left[\begin{array}{cccc}y_{11} & y_{12} & \ldots & y_{1 n} \\ y_{21} & y_{22} & \ldots & y_{2 n} \\ \ldots & \ldots & \ldots & \ldots \\ y_{N 1} & y_{N 2} & \cdots & y_{N J}\end{array}\right]$

where $y_{m j}$ is the local weight of alternative $\mathrm{m}$ with respect to 
criterion $j$. There are $N$ Alternatives and $J$ criteria. If the importance of criteria are incorporated in the form of multipliers $v_{m l}=d_{j} v_{m j}\left(\right.$ for all $j=1,2, \ldots, J$ and $\left.d_{l}=1\right)$ then final weights aggregated using DEA is proportional to the weighted sum $\sum \mathrm{j}=1 \mathrm{~d}_{\mathrm{j}} \mathrm{y}_{\mathrm{mj}}$ for alternative $m$.

\section{EMPIRICAL ILLUSTRATION}

Present research is an application based paper . Hierarchical structure as well as sample data for study has been adopted from Gupta R. \& Bhushan N[13].

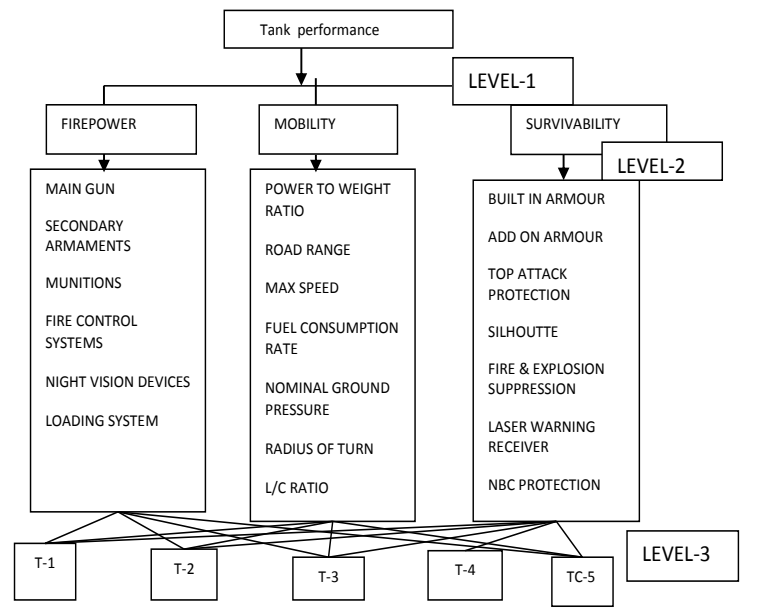

Fig .1 . Hierarchical structure to measure tank performance

The first two levels of the hierarchical structure contains the factors and sub-factors affecting tank performance. In the last level, one indicates the alternatives to be compares which include the tank whose performance has to be evaluated (say T-5) and some other well-known tanks whose performance can be treated as a standard for the comparative rating of T-5 (say T-1, T-2, etc.) . Further, the hierarchical structure in the above figure gives only few representative sub factors. An exhaustive list of sub factors can be obtained from [10,11] . Also, the factors which are amenable to qualitative appreciation may only be mentioned and other may be represented indirectly through these elements e.g. it may be easier for an expert to comment on the fire control system of a tank or the dispersion of shots rather than hit probabilities .

After structuring the hierarchy of factors affecting the tank performance, opinion of the experts has been obtained on the following issues :

- Comparative effects of various factors on the performance of the tank i.e. fire power, mobility and survivability.

- Comparative contribution of various sub factors on the factors mentioned above, e.g. effect of maximum firing range, accuracy, main gun caliber, etc. on the fire power of the tank.

- Relative ranking of each alternative tank with respect to each sub factor e.g. comparative ratings of tanks $\mathrm{T}-1, \mathrm{~T}-2, \mathrm{~T}-3$ etc. with respect to the accuracy of main gun .

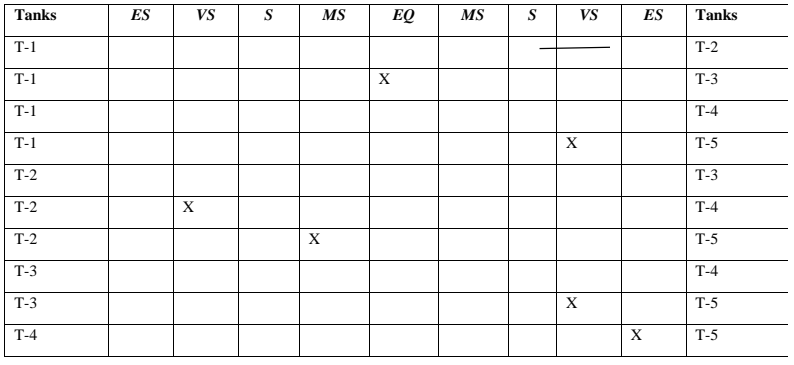

Fig.2. evaluation mark sheet for the relative comparison amongst different tanks

Note : The qualitative information is obtained in a suitably designed format enabling pairwise comparison of factors , subfactors and tanks (figure 2). This is communicated in the format by marking ' $X$ ' appropriately in one of the columns depending on intensity of comparisons, i.e. equal, moderate, strong, very strong, and extremely strong. The data obtained in this process are organized into square matrices, whose order is equal to the number of factors being compared at that stage.

It may be mentioned that in multiple criteria decision making problems , the opinion though consistent may be prejudiced or biased towards a specific aspect of system for example a soldier may emphasis on importance of main gun , ammunition , crew comfort, armour etc. and a scientist may considered the sighting system , fire control system etc. as more important factors in improving a tank performance. This may lead to personal bias in the analysis. It is therefore suggested that to eliminate such bias, the opinion of several experts from different disciplines may be elicited . To combine their opinion geometric mean of the corresponding values of the paired comparison at each stage in the hierarchy may be used for the final analysis. Local weights computed for the illustrative judgment matrices using EVM and the corresponding eigen values are shown in TABLE 3 below .

Table 3. Weightages for main factors

\begin{tabular}{|l|l|l|l|l|l|l|}
\hline & Mo & FP & Su & $\begin{array}{l}\text { Input } \\
\text { (Dummy) }\end{array}$ & $\begin{array}{l}\text { DEA } \\
\text { Efficiency }\end{array}$ & NW \\
\hline $\mathrm{Mo}$ & 1 & $1 / 3$ & $1 / 2$ & 1 & .334 & .2963 \\
\hline $\mathrm{FP}$ & 3 & 1 & 2 & 1 & 1 & 1 \\
\hline $\mathrm{Su}$ & 2 & $1 / 2$ & 1 & 1 & .67 & .56 \\
\hline
\end{tabular}

Table 4. Evaluation of relative comparison of tanks with respect to power and weight ratio

\begin{tabular}{|c|c|c|c|c|c|c|}
\hline & $\boldsymbol{T}-1$ & $\boldsymbol{T}-2$ & $\boldsymbol{T}-3$ & $\boldsymbol{T}-4$ & $\boldsymbol{T}-5$ & $\begin{array}{c}\text { Eigen } \\
\text { vector }\end{array}$ \\
\hline T-1 & 1 & $1 / 6$ & 1 & 4 & $1 / 7$ & .08 \\
\hline T-2 & 6 & 1 & 6 & 7 & 1 & .41 \\
\hline T-3 & 1 & $1 / 6$ & 1 & 4 & $1 / 7$ & .08 \\
\hline T-4 & $1 / 4$ & $1 / 7$ & $1 / 4$ & 1 & $1 / 9$ & .03 \\
\hline T-5 & 7 & 1 & 7 & 9 & 1 & .40 \\
\hline
\end{tabular}




\section{ANALYSIS (DEAHP approach) 3.1 Weightages for alternatives (Level -3 analysis)}

In the proposed approach, the entries of Table 1 are viewed as the performance (row-wise) of DMUs T-1, T-2 , T-3, T-4, T5 in terms of five outputs. The output-input structure of DEA is shown in Table1. In this case, to get the local weights of the Alternative (tanks T-1,T-2,T-3,T-4,T-5), the following model (based on DEA Model ) can be used[ Eq. (5)-Eq. (12)]:

Table 5. Alternatives (Level 3) from DEA Perspective

\begin{tabular}{|c|c|c|c|c|c|c|c|c|}
\hline & $\begin{array}{c}T- \\
1\end{array}$ & $\begin{array}{c}T- \\
2\end{array}$ & $\begin{array}{c}T- \\
3\end{array}$ & $\begin{array}{c}T- \\
4\end{array}$ & $\begin{array}{c}T- \\
5\end{array}$ & Input & $\begin{array}{c}\text { DEA } \\
\text { Eff. }\end{array}$ & $N W$ \\
\hline $\mathrm{T}-1$ & 1 & $1 / 6$ & 1 & 4 & $1 / 7$ & 1 & .4445 & .1951 \\
\hline T-2 & 6 & 1 & 6 & 7 & 1 & 1 & .99999 & 1 \\
\hline T-3 & 1 & $1 / 6$ & 1 & 4 & $1 / 7$ & 1 & .4445 & .1951 \\
\hline T-4 & $1 / 4$ & $1 / 7$ & $1 / 4$ & 1 & $1 / 9$ & 1 & .143 & .0731 \\
\hline T-5 & 7 & 1 & 7 & 9 & 1 & 1 & 1 & .9756 \\
\hline
\end{tabular}

\section{Model}

$$
\begin{aligned}
& \text { Max } z=v_{11}+1 / 6 v_{12}+v_{13}+4 v_{14}+1 / 7 v_{15} \\
& \text { s.t. } u_{11}=1 \\
& v_{11}+1 / 6 v_{12}+v_{13}+4 v_{14}+1 / 7 v_{15}-u_{11} \leq 0 \\
& 6 v_{11}+v_{12}+6 v_{13}+7 v_{14}+v_{15}-u_{11} \leq 0 \\
& v_{11}+1 / 6 v_{12}+v_{13}+4 v_{14}+1 / 7 v_{15}-u_{11} \leq 0 \\
& 1 / 4 v_{11}+1 / 7 v_{12}+1 / 4 v_{13}+v_{14}+1 / 9 v_{15}-u_{11} \leq 0 \\
& 7 v_{11}+v_{12}+7 v_{13}+9 v_{14}+v_{15}-u_{11} \leq 0 \\
& v_{11}, v_{12}, v_{13}, v_{14}, v_{15}, u_{11} \geq 0
\end{aligned}
$$

\begin{tabular}{|c|c|c|c|c|c|c|c|c|c|}
\hline $\begin{array}{l}\text { Sub } \\
\text { fact } \\
\text { ors }\end{array}$ & $\begin{array}{c}\mathbf{P} \\
\mathbf{W} \\
\mathbf{R}\end{array}$ & $\begin{array}{l}\mathbf{R} \\
\mathbf{R}\end{array}$ & $\begin{array}{l}\mathbf{N} \\
\mathbf{G} \\
\mathbf{P}\end{array}$ & $\begin{array}{c}\mathbf{F C} \\
\mathbf{R}\end{array}$ & $\begin{array}{l}\text { MS } \\
\text { PD }\end{array}$ & $\begin{array}{l}\mathbf{R} \\
\mathbf{O} \\
\mathbf{T}\end{array}$ & $\begin{array}{l}\text { L/ } \\
\text { C }\end{array}$ & $\begin{array}{l}\mathrm{V} \\
\mathbf{O} \\
\mathbf{C}\end{array}$ & $\begin{array}{c}\mathbf{M} \\
\mathbf{o}\end{array}$ \\
\hline RW & 1 & 1 & .92 & .2 & 1 & 1 & .4 & .4 & \\
\hline T-1 & $\begin{array}{l}.44 \\
45\end{array}$ & $\begin{array}{l}.7 \\
5\end{array}$ & .78 & $\begin{array}{l}.56 \\
25\end{array}$ & .395 & $\begin{array}{c}.27 \\
5\end{array}$ & .26 & .2 & $\begin{array}{l}.54 \\
10\end{array}$ \\
\hline T-2 & 1 & $\begin{array}{l}.8 \\
2\end{array}$ & .63 & 1 & 1 & 1 & 1 & .85 & 1.0 \\
\hline T-3 & $\begin{array}{l}.44 \\
45\end{array}$ & 1 & 1 & $\begin{array}{l}.43 \\
75\end{array}$ & .184 & $\begin{array}{c}.27 \\
5\end{array}$ & $\begin{array}{c}.20 \\
9\end{array}$ & $\begin{array}{c}.27 \\
5\end{array}$ & .58 \\
\hline $\mathrm{T}-4$ & $\begin{array}{c}.14 \\
3\end{array}$ & $\begin{array}{l}7 \\
14\end{array}$ & 1 & $\begin{array}{l}.43 \\
75\end{array}$ & .184 & $\begin{array}{c}.27 \\
5\end{array}$ & $\begin{array}{c}.20 \\
9\end{array}$ & $\begin{array}{c}.17 \\
5\end{array}$ & $\begin{array}{l}.46 \\
71\end{array}$ \\
\hline T-5 & 1 & $\begin{array}{c}.3 \\
92\end{array}$ & .23 & $\begin{array}{c}.15 \\
7\end{array}$ & .95 & $\begin{array}{c}.77 \\
5\end{array}$ & $\begin{array}{l}.65 \\
11\end{array}$ & 1 & $\begin{array}{l}.75 \\
16\end{array}$ \\
\hline
\end{tabular}

\subsection{Computation of final weights}

We can now apply the DEA approach again to aggregate the local weights obtained from previous data to generate final weights which will give me the mobility of tanks as follows:

Table 6. Computation of final weights
Aggregation using DEA using the local weights of sub factors: In this case, again the DEA model has been applied for the local weights in Table 5. The local weights are considered as outputs of alternatives, and a dummy input is introduced. For example, to get the final weight of alternative T1, the following model can be used [ Eq. (13)-Eq. (27)]:

\section{Model}

$\operatorname{Max} \mathrm{z}=.4445 \mathrm{v}_{11}+.75 \mathrm{v}_{12}+.78 \mathrm{v}_{13}+.5625 \mathrm{v}_{14}+.395 \mathrm{v}_{15}+.275$

$\mathrm{v}_{16}+.26 \mathrm{v}_{17}+.2 \mathrm{v}_{18}$

s.t. $\mathrm{u}_{11}=1$

$.4445 \mathrm{v}_{11}+.75 \mathrm{v}_{12}+.78 \mathrm{v}_{13}+.5625 \mathrm{v}_{14}+.395 \mathrm{v}_{15}+.275 \mathrm{v}_{16}$

$+.26 \mathrm{v}_{17}+.2 \mathrm{v}_{18}-\mathrm{u}_{11} \leq 0$

$\mathrm{v}_{11}+.8214 \mathrm{v}_{12}+.63 \mathrm{v}_{13}+\mathrm{v}_{14}+\mathrm{v}_{15}+\mathrm{v}_{16}+\mathrm{v}_{17}+.85 \mathrm{v}_{18}-\mathrm{u}_{11} \leq 0$ (16)

$.4445 \mathrm{v}_{11}+\mathrm{v}_{12}+\mathrm{v}_{13}+.4375 \mathrm{v}_{14}+.184 \mathrm{v}_{15}+.275 \mathrm{v}_{16}+.11 \mathrm{v}_{17}+.209$ $\mathrm{v}_{18}-\mathrm{u}_{11} \leq 0$

$.143 \mathrm{v}_{11}+.714 \mathrm{v}_{12}+\mathrm{v}_{13}+.4375 \mathrm{v}_{14}+.184 \quad \mathrm{v}_{15}+.275 \mathrm{v}_{16}$ $+.209 \mathrm{v}_{17}+.175 \mathrm{v}_{18^{-}} \mathrm{u}_{11} \leq 0$

$\mathrm{v}_{11}+.392 \mathrm{v}_{12}+.23 \mathrm{v}_{13}+.157 \mathrm{v}_{14}+.95 \mathrm{v}_{15}+.775 \mathrm{v}_{16}+.6511 \mathrm{v}_{17}+$

$\mathrm{v}_{18}-\mathrm{u}_{11} \leq 0$

$\mathrm{v}_{11}=\mathrm{v}_{12}$

$\mathrm{v}_{11}=1.084 \mathrm{v}_{13}$

$\mathrm{v}_{11}=5 \mathrm{v}_{14}$

$\mathrm{v}_{11}=\mathrm{v}_{15}$

$\mathrm{v}_{11}=\mathrm{v}_{16}$

$\mathrm{v}_{11}=2.5 \mathrm{v}_{17}$

$\mathrm{v}_{11}=2.5 \mathrm{v}_{18}$

$\mathrm{v}_{11}, \mathrm{v}_{12}, \mathrm{v}_{13}, \mathrm{v}_{14}, \mathrm{v}_{15}, \mathrm{v}_{16}, \mathrm{v}_{17}, \mathrm{v}_{18}, \mathrm{u}_{11} \geq 0$

The optimal objective function value of Model, when solved, will give the final weight of alternative Tank $-\mathrm{T} 1$. To get the final weight of other alternatives, models similar to the above model should be solved by changing the objective function. Using the values of local weights of subfactors, the additional constraints is introduced in the DEA model( given by (A)) that calculates the final weight (mobility) of DMU(tank T-1) .The resulting final weights of alternatives which gives the mobility of tanks, shown in the last column of Table 4, are $0.5410,1.000, .5842, .4671$ and 0.7516 .

The final weights are proportional to the weighted sum of local weights. For example, for alternative tank- T1, the weighted sum can be calculated as $[(0.4445 * 1)+(0.75 * 1)$ $+\quad(.78 * 0.9231)+\left(.5625^{*}\right.$ $\left.0.2)+(.395 * 1)+\left(.275^{*} 1\right)+(.26 * .4)+(.2 * .4)\right]=2.8630$. The weighted sum for the five alternatives are 2.8630 , $5.3284,3.8952,3.2677$ and 4.0211 which are proportional to $0.5410,1.000, .5842, .4671$ and 0.7516 . Similarly we can obtain firepower and survivability of the tanks .

\subsection{Performance rating of tanks}

Finally the performance rating of tanks can be computed by again using the same DEAHP approach as discussed above . In this case local priorities or the relative weightage of three main factors (mobility, firepower \&survivability) is taken into consideration. Performance index of various tanks comes out as the final weights of different alternatives (tanks T-1, T2,T-3,T-4,T-5). 
Table 7. Performance ratings of the tanks

\begin{tabular}{|c|c|c|c|c|c|}
\hline $\begin{array}{c}\text { Char- } \\
\text { acteristics }\end{array}$ & Mo & FP & Su & TPI & PR \\
\hline RW & .334 & 1 & .67 & & \\
\hline T-1 & .5410 & .5 & .578 & .546 & 1.0 \\
\hline T-2 & 1 & 1 & 1 & 1.00 & 1.83 \\
\hline T-3 & .5842 & .42 & .367 & .495 & .9053 \\
\hline T-4 & .4671 & .212 & .182 & .343 & .6272 \\
\hline T-5 & .7516 & .94 & .94 & .8372 & 1.531 \\
\hline
\end{tabular}

For example, to get the final weight of tank $-\mathrm{T} 1$, the following model has been used [ (Eq. (28)-Eq. (37)].

\section{Model}

$$
\begin{aligned}
& \text { Max } \mathrm{z}=.5410 \mathrm{v}_{11}+.5 \mathrm{v}_{12}+.578 \mathrm{v}_{13} \\
& \text { s.t. } \mathrm{u}_{11}=1 \\
& .5410 \mathrm{v}_{11}+.5 \mathrm{v}_{12}+.578 \mathrm{v}_{13}-\mathrm{u}_{11} \leq 0 \\
& \mathrm{v}_{11}+\mathrm{v}_{12}+\mathrm{v}_{13}-\mathrm{u}_{11} \leq 0 \\
& .5842 \mathrm{v}_{11}+.42 \mathrm{v}_{12}+.367 \mathrm{v}_{13}-\mathrm{u}_{11} \leq 0 \\
& .4671 \mathrm{v}_{11}+.212 \mathrm{v}_{12}+.182 \mathrm{v}_{13}-\mathrm{u}_{11} \leq 0 \\
& .7516 \mathrm{v}_{11}+.94 \mathrm{v}_{12}+.94 \mathrm{v}_{13}-\mathrm{u}_{11} \leq 0 \\
& \mathrm{v}_{11}=3 \mathrm{v}_{12} \\
& \mathrm{v}_{11} 2 \mathrm{v}_{13} \\
& \mathrm{v}_{11}, \mathrm{v}_{12}, \mathrm{v}_{13}, \mathrm{u}_{11} \geq 0
\end{aligned}
$$

We can infer from the results of the above analysis that the performance rating of tank T-5 is 1.54 times the performance rating of tank T-1. For a comparison of cost-effectiveness of two tanks, their relative ratings can be used as effectiveness index. For example here if we consider tank T-2, it is approximately twice as efficient as compared to tank $\mathrm{T}-1$.

\section{CONCLUSIONS}

An attempt here has been made to provide an alternative approach to the traditional AHP method for the computation of local weights or priorities and the final weights .For a perfectly consistent judgement matrices this approach gives the similar weights as given by AHP approach whereas for inconsistent matrices it tries to remove in consistency. Further when we compute the final weights we find that the final weights are weighted sum of local weights. The relative weightage of each factor, viz. ,mobility, firepower \& survivability, is suitably aggregated along with the relative weightage of each sub factor and the ratings of each sub factor and the ratings of each tank with respect to each sub factor, to give an overall performance index of each tank. From the tanks performance index , performance rating of each tank can be calculated.

\section{FUTURE DIRECTIONS}

Present paper is an application based research work which makes use of Hybrid DEAHP approach for measuring the efficiency of the selected armored vehicles (battle tanks) and selecting the most appropriate one amongst them based on the performance rating . Readers can further make use of other hybrid techniques such as hybrid analytic network process and zero one goal programming $[13,14]$ as an extension of the present paper.

\section{ACKNOWLEDGEMENTS}

Authors are thankful to Defence Research and Development Organization, Ministry of Defence, New Delhi, India for the motivation to conduct this research.

\section{REFERENCES}

[1] Saaty , T.L. 1980. How to make a decision . European Journal of Operational Research, 48(1), 9-26.

[2] Saaty, T.L. 1980. The Analytic Hierarchy Process: Planning, Priority Setting and Resource Allocation. New York: McGraw-Hill 1980.

[3] Golden, B.L., Wasil, E.A. and Harker ,P.T (eds).1989. The Analytic Hierarchy Process , Applications and studies.

[4] Terry, T.W., Jackson,S.R., Ryley, C.E.S. , Jones, B.E. and Wormell , P.J. 1991. Fighting vehicles Brassey's land warfare series, 7, Brassey's Defence publishers, U.K. , 289-296.

[5] Gazibey,Y., Kantemir, O. and Demirel ,A. 2015. Interaction among the criteria affecting main battle tank selection : an analysis with DEMATEL method, Defence Science Journal , 65(5), 345-355.

[6] Hilmes,R. 1987. Main battle tanks , development in design since 1945. Brassey's defense publishers , U.K. , $35,50-69$.

[7] Gupta, R. and Bhushan, N. 1996. Performance evaluation of battle tanks. Defence Science Journal , 46(2), 115-119.

[8] M.J. Farrel, M.J. 1957. The measurement of productive efficiency. Journal of Royal Statistical Society (A), 120, 253-81.

[9] Charnes, A., Cooper, W.W., Lewinand , A.Y., Seiford ,L.M. 1994. Data envelopment analysis: theory, methodology and applications. Boston: Kluwer .

[10] Cooper, W.W., Seiford, L.M. and Tone, K. 2000. Data envelopment analysis: a comprehensive text with models, applications, references and DEA-solver software, Boston: Kluwer Academic Publishers .

[11] Norman , M. and Stoker,B.1991. Data envelopment analysis: the assessment of performance. Chichester: Wiley.

[12] Ramanathan, R. 2007. Data envelopment analysis for weight derivation and aggregation in the Analytic Hierarchy Process, Computers and Operations Research, 1289-1307.

[13] Chen, R.S. and Shyu ,J.S. 2005. Selecting a weapon system using zero one goal programming and Analytic Network Process. Journal of Information and Optimization Sciences , 27(2), 379-399.

[14] Mon , D.L., Cheng ,C.H. , Ling , J.H. 1994. Evaluating weapon system using fuzzy Analytic Hierarchy Process based on Entropy Weights , Fuzzy sets and Systems, 62, 127-134. 


\section{APPENDIX}

\section{Abbreviations}

PWR : Power to weight ratio

RR Road range (RR)

NGP : Nominal ground pressure

FCR: Fuel consumption rate (FCR)

MSPD: Maximum speed (MSPD)

ROT : Radius of turn (ROT)

L/C : Length pitch ratio
VOC: Vertical obstacle crossing

Mo. : Mobility

FP : Firepower

Su : Survivability

NW : Normalized weight (using AHP)

TPI: Tank performance index

RW : Relative weightage

DEA Eff : DEA Efficiency 